Check for updates

Cite this: RSC Adv., 2018, 8, 18604

\title{
A defective MOF architecture threaded by interlaced carbon nanotubes for high-cycling lithium-sulfur batteries $\dagger$
}

\author{
Yujie Pu, ${ }^{\text {ab }}$ Wubin Wu, ${ }^{c}$ Jianyu Liu, ${ }^{\text {ab }}$ Tao Liu, ${ }^{\text {ab }}$ Fei Ding, ${ }^{\text {*b }}$ Jing Zhang ${ }^{b}$ \\ and Zhiyuan Tang (D) *a
}

Metal organic frameworks (MOFs) have been deemed among the most promising sulfur hosts for lithiumsulfur (Li-S) batteries owing to their high specific surface areas, novel pore structures and open metal sites. However, their highly coordinated, electronically insulating and structurally unstable nature overshadows the merits of MOFs to a great extent. In this work, a novel UiO-66/carbon nanotube (UC) composite was initially synthesized via a facile one-pot synthesis strategy, in which abundant linker-missing defects were caused by introduced competitive coordination. Meanwhile, flexible and interlaced carbon nanotubes (CNTs) throughout mechanically stable UiO-66 nanoparticles constructed a reliable conductive network. Because of its superior structural stability, high electronic conductivity and strong polysulfide chemisorption, the $U C$ architecture as the sulfur cathode in Li-S batteries shows stable cycling, delivering an initial capacity of $925 \mathrm{~mA} \mathrm{~h} \mathrm{~g}$ at $0.5 \mathrm{~A} \mathrm{~g}^{-1}$ and a very low fading rate over 800 cycles of $0.071 \%$ per cycle at $1 \mathrm{~A} \mathrm{~g}^{-1}$. A strong chemical affinity between coordination defects and LiPSs was revealed by first principles calculations and apparent absorption, which indicates significant entrapment of soluble polysulfides by the UC composite, thus leading to the outstanding cycling performance of SaUC electrodes.

Received 14th March 2018 Accepted 29th April 2018

DOI: $10.1039 / c 8 r a 02254 b$

rsc.li/rsc-advances side, then back and forth transfer between two electrodes, generating the notorious shuttle effect, which will cause low coulombic efficiency, severe self-discharge, rapid capacity decay, etc. . $^{4,70-12}$

Though enormous efforts have been made to overcome these deficiencies, most previous work was mainly focused on the impregnation of sulfur into various carbon materials owing to the fast electronic transfer of carbon materials in sulfur electrochemistry by virtue of their excellent conductivity. ${ }^{13-20}$ Unfortunately, the interaction strength between nonpolar carbon materials and polar lithium polysulfides (LiPSs) is too weak to effectively suppress the out-diffusion of soluble polysulfides, indicating a serious capacity recession after long-term cycling. ${ }^{10,21,22}$

In recent years, polar host materials were successively reported that can display more powerful entrapment of polysulfides, benefiting from strong chemical interactions, such as metal oxides, ${ }^{23-26}$ sulfides, ${ }^{27-31}$ nitrides, ${ }^{32-35}$ conductive polymers $^{36,37}$ and MXene nanosheets. ${ }^{38,39}$ As a new kind of 3D porous polar material, metal-organic frameworks (MOFs) with high surface areas, sophisticated pore structures and open metal sites exhibit dual confinement, from physical barriers and chemical interactions with active sulfur species at the molecular level, effectively alleviating the soluble LiPS shuttle problems. ${ }^{40-45}$ In addition, the diversity of metal sites and ligands and the controllability of the pore structures bring great 
flexibility to MOFs selected as sulfur host materials. ${ }^{\mathbf{4 4 6}}$ However, the high degree of coordination in MOFs means it is difficult to afford them lots of coordinatively unsaturated metal ions as active sites (or Lewis acid sites). For example, UiO-66 (Zr-MOF), ${ }^{47}$ one of the highly coordinated MOFs, exhibits exceptional mechanical strength and chemical stability, far above those of other benchmark MOF hosts such as MOF-5, ZIF-8 and HKUST-1, approaching that of zeolites. ${ }^{\mathbf{4 8 , 4 9}}$ Moreover, the insulating and brittle nature of MOFs severely restrains the electrochemical kinetics of sulfur and the mechanical stability of the electrode, ${ }^{50-52}$ without ensuring a high capacity output and long-term cycling. Hence, the use of MOF materials as sulfur hosts has been mainly limited to their derived porous carbon materials, ${ }^{53-56}$ which greatly limits the value of the application of MOFs to $\mathrm{Li}-\mathrm{S}$ batteries.

Herein, novel UiO-66/CNTs (UC) composites as sulfur hosts are prepared and reported for the first time via a simple one-pot synthesis using a competitive coordination principle. The robust UiO-66 nanoparticles were implanted and threaded with flexible CNTs to construct reliable 3D conductive networks and also to strengthen the flexibility of the host frameworks. Meanwhile, benzoic acid as a coordinative modulator triggers forceful competition with the original ligands for coordination with the central metal core $\left(\mathrm{Zr}^{4+}\right)$, and a subsequent thermal activation leads to abundant linker-missing defects, which greatly increases the number of active sites in the UiO-66 framework. The smart and facile experimental design not only retains the original virtues of MOFs, including high specific surface area and subtle porous structure, but also obviously boosts the electronic conductivity and the chemisorption of polysulfides.

\section{Experimental section}

\section{Preparation of UC composites}

UC composites were fabricated via a simple solvothermal process. Before the synthesis, CNTs (diameter: $<8 \mathrm{~nm}$, length: 10-30 $\mu \mathrm{m}$, Nanjing XF Nano) were charged negatively in concentrated nitric acid for $48 \mathrm{~h}$. Firstly, anhydrous zirconium tetrachloride $\left(\mathrm{ZrCl}_{4}\right)$ (0.6 g, purity: 98\%, ACROS ORGANICS) was dissolved in $120 \mathrm{~mL}$ DMF by sonicating for $10 \mathrm{~min}$. Then, the prefunctionalized CNTs were dispersed in the above mentioned DMF solution by constantly sonicating for $2 \mathrm{~h}$ to form uniform solutions with different CNT concentrations $\left(2 \mathrm{mg} \mathrm{mL}{ }^{-1}, 3 \mathrm{mg}\right.$

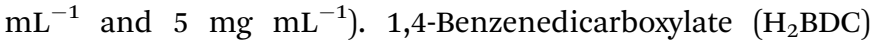
( $0.4 \mathrm{~g}$, purity: 99\%, Innochem) and benzoic acid ( $8.8 \mathrm{~g}$, purity: 98\%, ACROS ORGANICS) were added into these solutions. The final solutions were moderately and continuously stirred for $24 \mathrm{~h}$ in an oil bath at $120{ }^{\circ} \mathrm{C}$. The obtained black precipitates were filtered and washed with fresh DMF several times, and then dried overnight under vacuum at $150{ }^{\circ} \mathrm{C}$ and finally activated at $250{ }^{\circ} \mathrm{C}$ in a vacuum tube furnace for $4 \mathrm{~h}$. These activated products were denoted UC-2, UC-3 and UC- 5 with three different CNT concentrations. Besides, pure UiO-66 was also synthesized.

\section{Preparation of the S@UC series, S@UiO-66 and S@CNTs}

Firstly, sublimed sulfur powder was dissolved in $\mathrm{CS}_{2}$ solvent to form a $7 \mathrm{mg} \mathrm{mL}^{-1}$ sulfur $\mathrm{CS}_{2}$ solution, and then $150 \mathrm{mg}$ of UC composite was immersed in $50 \mathrm{~mL}$ of the above solution and dried slowly at $40{ }^{\circ} \mathrm{C}$. Finally, the mixture was placed in a tube furnace and then heated at $155{ }^{\circ} \mathrm{C}$ for $12 \mathrm{~h}$ under an Ar atmosphere. For experimental comparisons, S@UiO-66 and S@CNTs were also fabricated using the same process.

\section{Material characterization}

$\mathrm{X}$-ray diffraction (XRD) analysis of all samples was investigated using a diffractometer (DX-2700) with $\mathrm{Cu}-\mathrm{K} \alpha$ radiation $(\lambda=0.154$ $\mathrm{nm})$ at a scan rate of $10^{\circ} \mathrm{min}^{-1}$. The microstructures were observed using scanning electron microscopy (SEM, HITACHIS4800) and transmission electron microscopy (TEM, JEOL2100F). The pore structure was determined using a BrunauerEmmett-Teller surface area analyzer (BET, JW-BK122W). The electronic conductivity tests were evaluated at room temperature using a four-point probe (RTS-8, four probe technology Co., Ltd, Guangzhou, China) with a probe distance of $1 \mathrm{~mm}$, and the tested samples were previously pressed into a round disk with a diameter of $16 \mathrm{~mm}$ and a thickness of $1 \mathrm{~mm}$. Thermal analysis was performed on a thermogravimetric analyzer (TGA, Q5000IR) from room temperature to $700{ }^{\circ} \mathrm{C}$ with a heating rate of $10{ }^{\circ} \mathrm{C} \mathrm{min} \mathrm{m}^{-1}$ under an $\mathrm{N}_{2}$ atmosphere. X-ray photoelectron spectroscopy (XPS) analysis was conducted on a PHI-5000C ESCA instrument with a monochromatic $\mathrm{Al} \mathrm{K} \alpha(1486.6 \mathrm{eV}) \mathrm{X}$-ray source.

\section{Lithium sulfide adsorption test}

Before adsorption testing, all the samples and bottles were dried under vacuum at $150{ }^{\circ} \mathrm{C}$ for $12 \mathrm{~h}$. Firstly, a $20 \mathrm{mmol} \mathrm{L}^{-1}$ $\mathrm{Li}_{2} \mathrm{~S}_{6}$ solution was synthesized by mixing $\mathrm{Li}_{2} \mathrm{~S}$ and sulfur with a molar mass ratio of $1: 5$ in a mixture of 1,3-dioxolane (DOL) and dimethoxymethane (DME) $(\mathrm{v} / \mathrm{v}=1: 1)$ at $60{ }^{\circ} \mathrm{C}$ for $72 \mathrm{~h}$. Then, a $5 \mathrm{mmol} \mathrm{L}^{-1} \mathrm{Li}_{2} \mathrm{~S}_{6}$ diluent was obtained from the asprepared $\mathrm{Li}_{2} \mathrm{~S}_{6}$ solution. Finally, each bottle contained $5 \mathrm{~mL}$ of $5 \mathrm{mmol} \mathrm{L}^{-1} \mathrm{Li}_{2} \mathrm{~S}_{6}$ solution and $50 \mathrm{mg}$ sample. All of the adsorption experiment processes were conducted in an $\mathrm{Ar}$ gas filled glove box $\left(\mathrm{O}_{2}, \mathrm{H}_{2} \mathrm{O}<0.1 \mathrm{ppm}\right)$.

\section{Electrochemical measurements}

The electrochemical performances of the S@UC electrodes were evaluated in a 2430-type coin cell. The cathode consisted of $80 \mathrm{wt} \%$ sulfur composite materials, $10 \mathrm{wt} \%$ conductive additives (super P) and $10 \mathrm{wt} \%$ binders (PVDF), which were stirred in 1-methyl-2-pyrrolidinone (NMP) solvent to form a slurry, then coated onto $\mathrm{Al}$ foil with a doctor blade and dried at $60{ }^{\circ} \mathrm{C}$ under vacuum for $12 \mathrm{~h}$ and eventually cut into pieces with a diameter of $16 \mathrm{~mm}$ (average sulfur loading: $\sim 2.0 \mathrm{mg}$ per piece). All test cells were assembled in an Ar gas filled glove box $\left(\mathrm{O}_{2}, \mathrm{H}_{2} \mathrm{O}<0.1\right.$ ppm). Metal lithium foil was used as the anode and Celgard 2400 membrane used as the separator. $1 \mathrm{~mol} \mathrm{~L}^{-1}$ bis(trifluoromethylsulfonyl)imide (LiTFSI, purity: 99\%, Aldrich) dissolved in 1,2-dimethoxymethane (DME, purity: 99.9\%, Aldrich)/ 1,3-dioxolane (DOL, purity: 99.9\%, Aldrich) (by v/v: $1: 1$ ) with $2 \mathrm{wt} \% \mathrm{LiNO}_{3}$ was used as the electrolyte. The electrolyte/sulfur ratio of each coin cell was $40 \mu \mathrm{L} \mathrm{mg}^{-1}$.

The charge-discharge procedure was carried out using a Land CT2001 battery tester in the voltage region of 1.7-2.8 V. 
Both the CV tests carried out between $1.7 \mathrm{~V}$ and $2.8 \mathrm{~V}$ with a scan rate of $0.05 \mathrm{mV} \mathrm{s}^{-1}$ and the EIS measurements conducted over a frequency range of $100 \mathrm{kHz}$ to $100 \mathrm{MHz}$ with an amplitude of $5 \mathrm{mV}$ were achieved on a Princeton (PARSTAT 2273) electrochemical workstation. All of the specific capacity calculations were based on the mass of the element sulfur.

\section{Computational methods}

In order to study the interactions between defective UiO-66 and LiPSs, first-principles calculations were carried out based on density functional theory (DFT) as implemented in the VASP code. ${ }^{57}$ The projector augmented wave method and PerdewBurke-Ernzerhof exchange-correlation functions of the generalized gradient approximation (GGA) were utilized. ${ }^{58-60}$ The calculation system consists of a unit cell of Zr-MOF (intact UiO66, $\mathrm{D}_{1}$-UiO-66, $\mathrm{D}_{2}$-UiO-66 and $\mathrm{D}_{3}$-UiO-66, as shown in Fig. $\mathrm{S} 8$ and $\mathrm{S} 9 \dagger$ ) and $\mathrm{Li}_{2} \mathrm{~S}_{4}$ (as a representative of LiPSs). The systems consisting of Zr-MOF and LiPSs are surrounded by vacuum layers of at least $15 \AA$ in each direction to eliminate spurious interactions between each system and its image due to periodic boundary conditions. The plane-wave energy cut-off was set at $400 \mathrm{eV}$ and $\Gamma$-point sampling was used to make sure the total energies were converged to $10^{-4} \mathrm{eV}$. In addition, a dipole correction was applied in the calculations to account for any possible polarity and charger transfer. ${ }^{61}$ The binding energy $\left(E_{\mathrm{b}}\right)$ is defined as:

$$
E_{\mathrm{b}}=E_{\mathrm{MOF}}+E_{\mathrm{LiPS}}-E_{\mathrm{MOF}-\mathrm{LiPS}}
$$

where $E_{\mathrm{MOF}}, E_{\mathrm{LiPS}}$, and $E_{\mathrm{MOF}-\mathrm{LiPS}}$ represent the total energies of the UiO-66 unit, LiPSs and the combined systems, respectively. A larger positive value refers to a greater binding ability.

\section{Results and discussion}

A typical preparation procedure of UC composites as a sulfur host is illustrated in Fig. 1. On one hand, according to the electrostatic attraction, the electropositive $\mathrm{Zr}^{4+}$ of zirconium tetrachloride is easily attracted and adsorbed to the strongly electronegative oxygen functional groups from the surface of acid-treated CNTs, which contributes to intensive nucleation of UiO-66 on the CNTs. These small crystal nuclei anchored on the surface of the CNTs will grow and form UiO-66 nanocrystals by penetrating the CNTs, which can finally establish an outstanding 3D conductive network. On the other hand, a building unit of ideal UiO-66 is composed of an inner $\mathrm{Zr}_{6} \mathrm{O}_{4}(\mathrm{OH})_{4}$ core and 12 BDC linkers with full coordination, which cannot provide any available Lewis acid sites to anchor the LiPSs. $^{\mathbf{4 7 , 6 2}}$ Some studies have pointed out that acidic reagents as modulators can compete with $\mathrm{H}_{2} \mathrm{BDC}$ to coordinate $\mathrm{Zr}^{4+}$ to increase the number of active sites. ${ }^{63-65}$ In this paper, a quantity of benzoic acid as an additional ligand is used to forcefully trigger competitive coordination. After a thermal activation treatment, many coordination sites of the $\mathrm{Zr}^{4+}$ are exposed by eliminating unstructured benzoic acid linkers. These coordination defects may afford adequate active sites to immobilize polysulfides. We set up three DMF solutions with different CNT concentrations $\left(2 \mathrm{mg} \mathrm{mL}^{-1}, 3 \mathrm{mg} \mathrm{mL}^{-1}\right.$ and $5 \mathrm{mg}$ $\mathrm{mL}^{-1}$, respectively) to obtain the best balance between conductivity and LiPS entrapment in the UC composites. The resulting product series are correspondingly denoted UC-2, UC3 and UC-5, with a CNT content of $\sim 22.8 \%, 34.3 \%$ and $55.9 \%$, respectively. Sulfur impregnation into the as-synthesized UC composites was carried out through a combination of a facile immersion method and a traditional melt-diffusion process, where sulfur powder, with a large particle size, is dissociated into uniform nanosized particles in $\mathrm{CS}_{2}$ solvent and then more easily infiltrates the pores of UiO-66 with liquid sulfur at $155^{\circ} \mathrm{C}$. The desired S@UC hybrid series was finally obtained.

The morphological features of the as-prepared products were investigated. Fig. S1a and $\mathrm{b} \dagger$ show aggregates of small and intergrown UiO-66 particles (80-200 $\mathrm{nm})$. As seen from the SEM images of UC-3 (Fig. 2a and S2a-c $\dagger$ ), firstly, the octahedral UiO66 nanocrystals with a narrow size range of $\sim 300-500 \mathrm{~nm}$ were synthesized, suggesting that benzoic acid participates in the coordination between $\mathrm{Zr}^{4+}$ and $\mathrm{H}_{2}$ BDC ligands and, as the moderator, may suppress fast nucleation of UiO-66 grains. Furthermore, the TEM images (Fig. $2 b$ and $c$ and S2c, $d \dagger$ ) clearly show that long CNTs are not only inserted into all of the UiO-66 nanoparticles, but also connect these particles. UC-2 and UC-5 (Fig. S1c-f $\dagger$ ) show similar features to UC-3 in structural morphology, indicating the successful implantation of the conductive network into the UiO-66 octahedrons. Fig. 2 d shows that the morphological uniformity of the UC-3 is well preserved after the sulfur encapsulation process in the S@UC-3 hybrid. Successful encapsulation of sulfur into the cavities of the MOF architecture is intuitively confirmed by TEM analysis (Fig. 2e and $f$ ), and no obvious sulfur tracks exist on the surface of the UC-3 particles. To further probe the distribution of sulfur in the UC series, energy dispersive X-ray spectroscopy (EDS) was performed on S@UC-3 particles as a representative of the S@UC hybrids. The sulfur element mapping (in Fig. 2g) clearly shows that most sulfur uniformly distributes inside the MOF particles and small amounts of sulfur also exist in the CNTs, which is in good accordance with the carbon mapping and further confirmed by the line-scanning EDS measurements shown in Fig. 2h.

Fig. 3a shows the XRD patterns of pristine UiO-66 and the UC series. The UC series displays the same characteristic peaks from $5^{\circ}$ to $35^{\circ}$ as UiO- 66 , indicating that the introduction of CNTs and benzoic acid and a subsequent activation do not destroy the crystal structure of the UiO-66 framework. Strong orthorhombic sulfur peaks (PDF\#83-2283) in the XRD patterns of the S@UC series (Fig. S3 $\dagger$ ) reflect residual sulfur on the surface of the UC architectures after sulfur encapsulation. The weight ratio of sulfur in the three S@UC hybrids is $\sim 68 \mathrm{wt} \%$ from the TGA curves in Fig. 3b. As shown in Fig. 3c, UiO-66 and the UC series display very similar $\mathrm{N}_{2}$ adsorption/desorption behavior, in which a very strong absorption at low pressure $\left(<0.01\right.$ at $\left.P / P_{0}\right)$ is observed, revealing an abundant microporous nature. With increasing CNT content, a rise at high relative pressure $\left(>0.7\right.$ at $\left.P / P_{0}\right)$ appears in the isotherms of UC-3 and UC5 due to their mesoporous structures. The pore size distribution derived from NLDFT calculations clearly shows abundant 


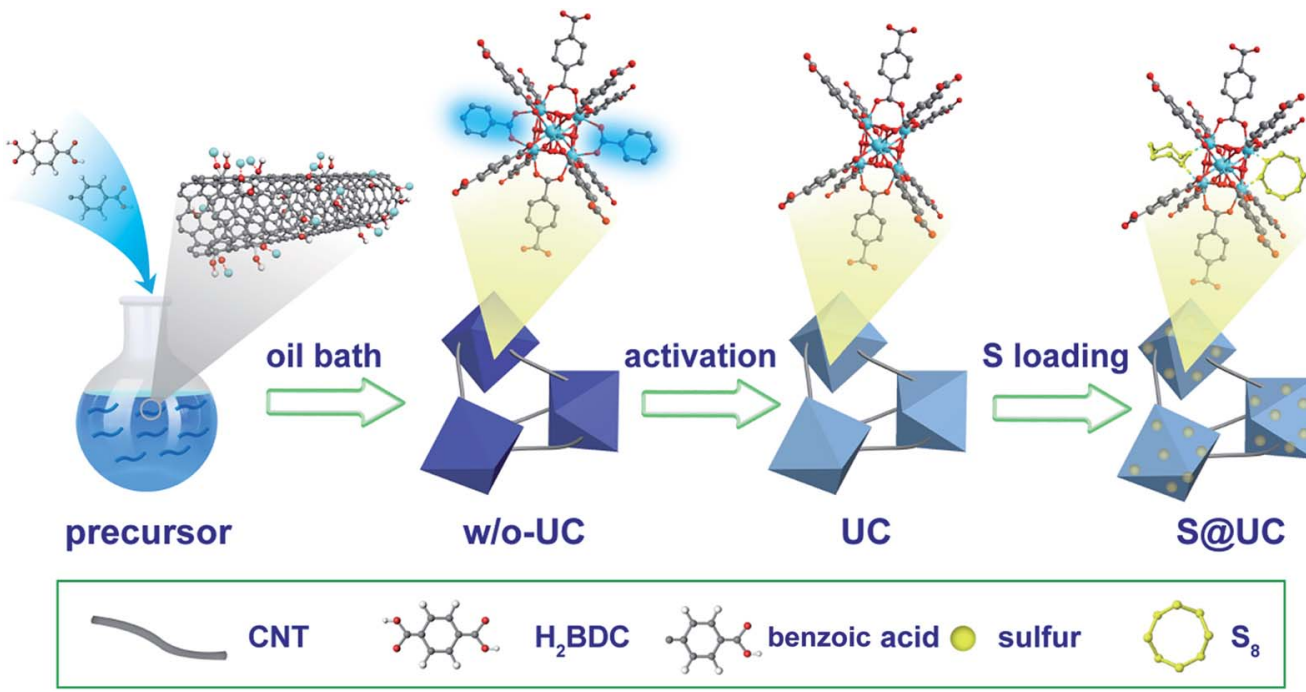

Fig. 1 Schematic illustration of the synthesis process of the UC architecture and S@UC composites.

microporosity and emerging mesoporosity (Fig. 3d). UiO-66 exhibits a high BET surface area of $1157 \mathrm{~m}^{2} \mathrm{~g}^{-1}$ and a large pore volume of $0.43 \mathrm{~cm}^{3} \mathrm{~g}^{-1}$. After adding CNTs with a low surface area of $278 \mathrm{~m}^{2} \mathrm{~g}^{-1}$, the UC series still maintains the high specific surface area properties of UiO-66 frameworks, viz. 976 $\mathrm{m}^{2} \mathrm{~g}^{-1}$ (UC-2), $863 \mathrm{~m}^{2} \mathrm{~g}^{-1}$ (UC-3) and $738 \mathrm{~m}^{2} \mathrm{~g}^{-1}$ (UC-5), respectively. Besides, their pore volume and average pore sizes are enlarged (Table S1†). After sulfur encapsulation, the specific surface areas of the UC series sharply decrease to $17.13 \mathrm{~m}^{2} \mathrm{~g}^{-1}$, $15.36 \mathrm{~m}^{2} \mathrm{~g}^{-1}$ and $6.62 \mathrm{~m}^{2} \mathrm{~g}^{-1}$, respectively, demonstrating a successful filling of sulfur into the cavities of the UC series.

High electronic conductivity, excellent structural stability and strong polysulfide adsorption are three crucial factors for assessing advanced sulfur hosting materials for $\mathrm{Li}-\mathrm{S}$ batteries. The electronic insulation of MOFs intrinsically defines a very low conductivity for UiO-66 (generally $<10^{-10} \mathrm{~S} \mathrm{~cm}^{-1}$ ). ${ }^{51}$

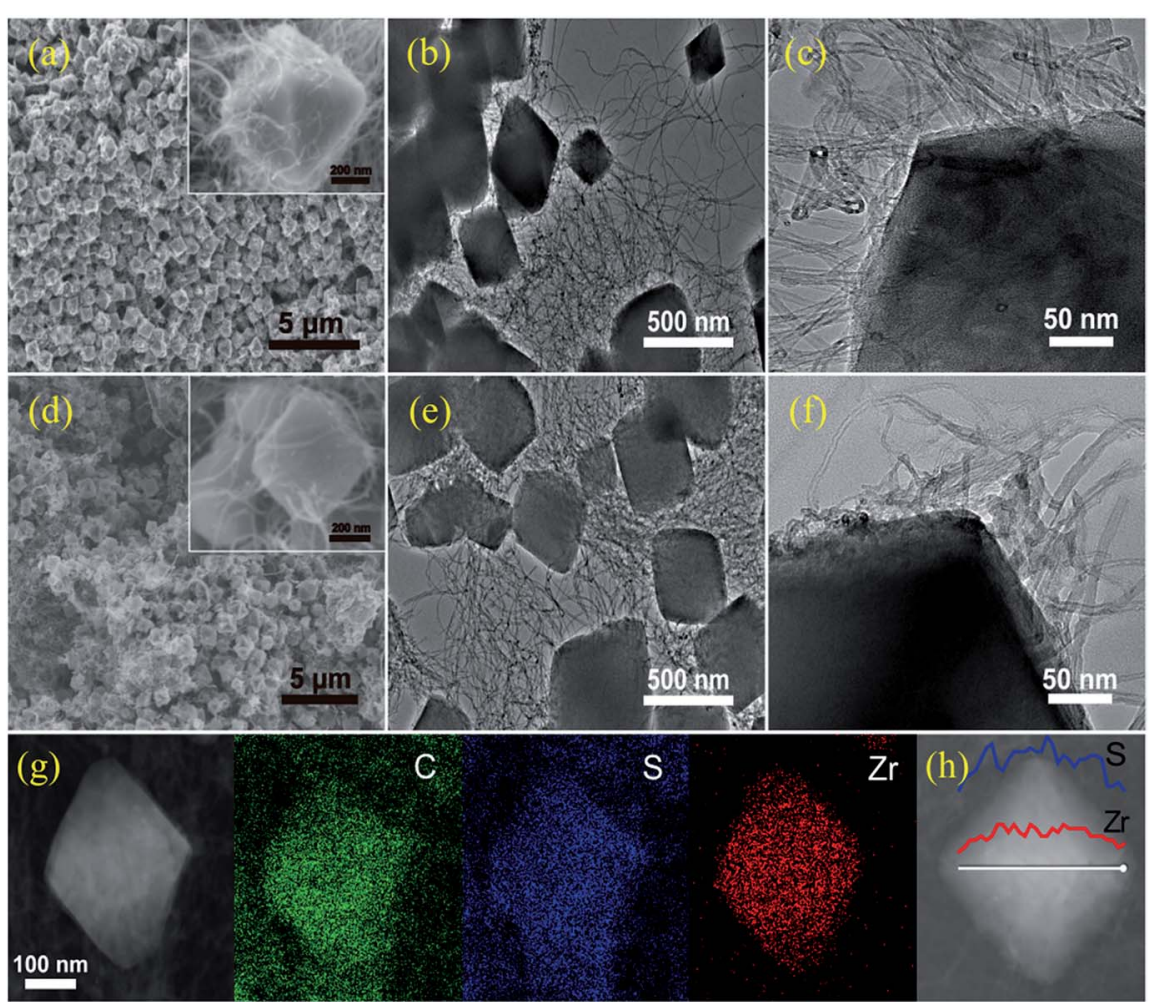

Fig. 2 SEM and TEM images of as-prepared (a)-(c) UC-3 and (d) - (f) S@UC-3; (g) and (h) elemental mapping and linear EDX element distributions of zirconium and sulfur of S@UC-3 hybrids. 
(a)
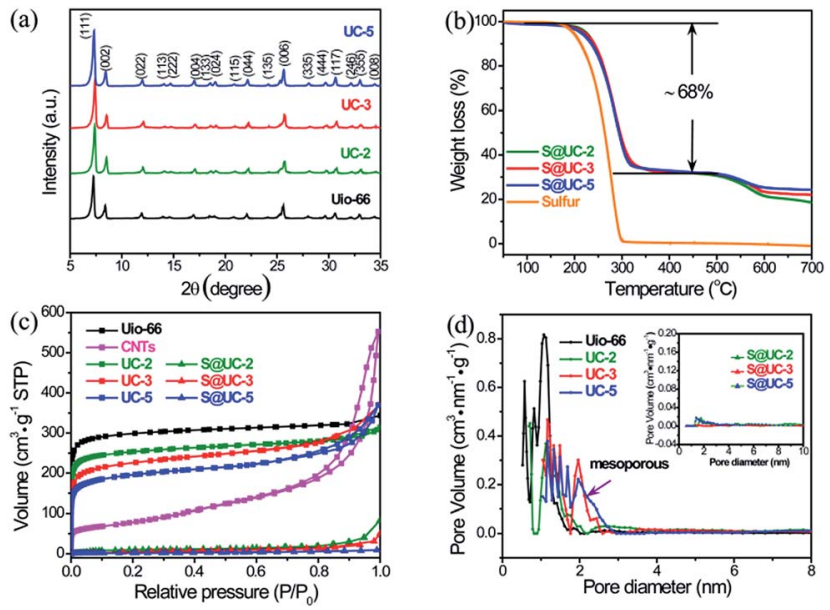

Fig. 3 (a) XRD patterns of UiO-66 and UC series samples. (b) TGA curves of S@UC-2, S@UC-3 and SaUC-5 hybrids. (c) $\mathrm{N}_{2}$ adsorption/ desorption isotherms at $77 \mathrm{~K}$ for CNTs, UiO-66, the UC series and the three corresponding S@UC hybrids. (d) Average pore size distribution of UiO-66, the UC series and the three corresponding S@UC hybrids using the $77 \mathrm{~K} \mathrm{~N}_{2}$ isotherms based on nonlocal density function theory (NLDFT).

Benefiting from construction of the 3D conductive CNT networks, the UC series exhibited dramatically improved conductivity at room temperature (UC-2: $8.69 \mathrm{~S} \mathrm{~cm}^{-1}$, UC-3: 12.54 $\mathrm{S} \mathrm{cm}^{-1}$ and UC-3: $13.68 \mathrm{~S} \mathrm{~cm}^{-1}$ ), far above that of pristine UiO-66 and the homologous mixtures of UiO-66 and CNTs with an equivalent ratio (denoted mix-2, mix-3 and mix-5, respectively), as shown in Fig. 4a. Thermogravimetric analysis (TGA) was performed to obtain traces of UC-3 both with and without activation (denoted w/o-UC-3) (Fig. 4b). Very high thermal stability was exhibited until a sharp degradation at $\sim 540{ }^{\circ} \mathrm{C}$ due to abundant linker connections and a high degree of $\mathrm{Zr}-\mathrm{O}$ coordination. A moderate weight loss of $\sim 7.6 \mathrm{wt} \%$ between $200{ }^{\circ} \mathrm{C}$ and $350{ }^{\circ} \mathrm{C}$ was observed in the trace of w/o-UC3. Apparently, the mass loss from the internal dehydroxylation of the $\mathrm{Zr}_{6} \mathrm{O}_{4}(\mathrm{OH})_{4}$ cluster (loss of $2 \mathrm{H}_{2} \mathrm{O}$ molecules) is negligible for a superstructural UiO-66 unit, ${ }^{47}$ indicating that additional linker vacancies might be generated by the removal of unstructural benzoic acid after activation.

X-ray photoelectron spectroscopy (XPS) measurements were performed to validate our reasoning on the linker-missing defects. In Fig. 4c, the $\mathrm{Zr} \mathrm{3d} \mathrm{spectra} \mathrm{is} \mathrm{split} \mathrm{into} \mathrm{two} \mathrm{typical}$ peaks corresponding to $3 \mathrm{~d}_{3 / 2}$ and $3 \mathrm{~d}_{5 / 2}$. For w/o-UC-3, a small chemical shift, compared with that of pristine UiO-66 $\left(\Delta E_{1}=\right.$

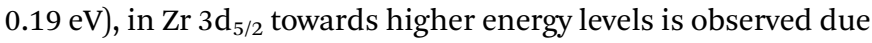
to the difference between benzoic acid and $\mathrm{H}_{2} \mathrm{BDC}$ ligands coordinating with the $\mathrm{Zr}^{4+}$. After activation, the $\mathrm{Zr} 3 \mathrm{~d}_{5 / 2}$ peak remarkably shifts positively to the higher level of $183.76 \mathrm{eV}$ $\left(\Delta E_{2}=0.60 \mathrm{eV}\right)$, reflecting the weakness of additional electronpairs around the coordinated orbitals of $\mathrm{Zr}^{4+}$. Encapsulation of sulfur into UC-3 triggers a larger $\mathrm{Zr} 3 \mathrm{~d}_{5 / 2}$ level shift $\left(\Delta E_{2}=1.22\right.$ $\mathrm{eV}$ ) from $183.76 \mathrm{eV}$ to $182.54 \mathrm{eV}$, indicating an abundant supply of coordinated electron-pairs from electron-rich sulfur. To verify that the coordination vacancies of $\mathrm{Zr}^{4+}$ result from removing
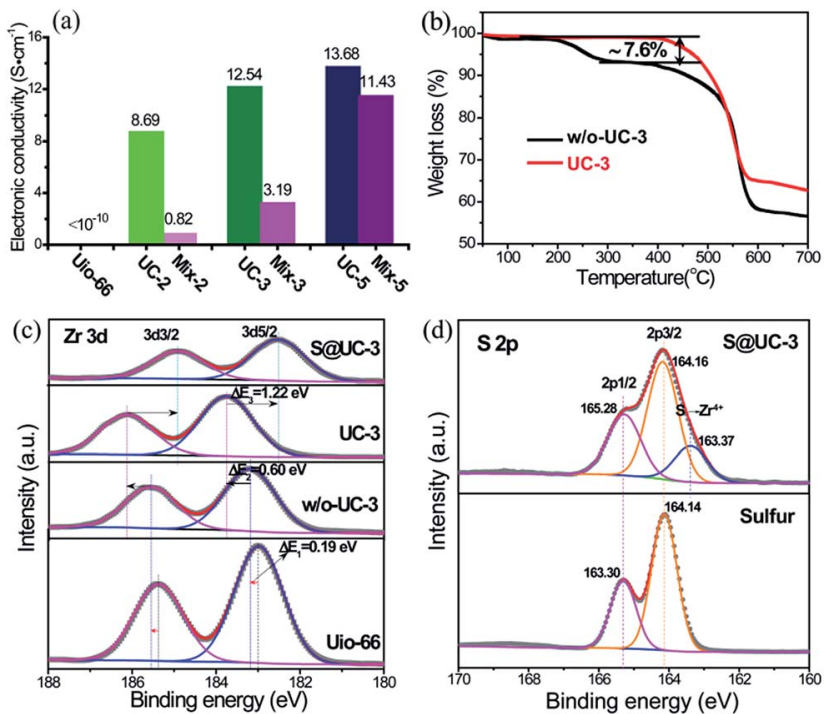

Fig. 4 (a) Electronic conductivity of the UC series and the corresponding mixtures with the equivalent ratio of UiO-66 and CNTs measured using the four-probe method at room temperature. (b) TGA curves of UC-3 with activation and without activation (w/o-UC-3). (c) $\mathrm{Zr} 3 \mathrm{~d}$ XPS spectra of UiO-66, w/o-UC-3, UC-3 and S@UC-3. (d) S 2p spectra of sulfur and SQUC-3.

benzoic acid linkers, the $\mathrm{C}$ 1s and $\mathrm{O}$ 1s spectra were quantitatively analyzed (in Fig. S4 and Table S2 $\dagger$ ). In its C 1s spectrum, pristine UiO-66 shows two peaks assigned to the $\mathrm{C}-\mathrm{C}(284.79 \mathrm{eV})$ bonds of the benzene ring and the terminal $\mathrm{O}=\mathrm{C}-\mathrm{O}(289.80 \mathrm{eV})$ from the BDC linkers. Two additional peaks at $285.62 \mathrm{eV}$ and $286.74 \mathrm{eV}$ from the oxygen functional groups $(\mathrm{C}-\mathrm{O}$ and $\mathrm{C}=\mathrm{O})$ of CNTs appear in w/o-UC-3 almost without any change after activation in UC-3, owing to negligible contributions of CNTs to the weight loss in the activation process. Additionally, an obvious content decrease from $29.09 \%$ to $24.49 \%$ of $\mathrm{C}-\mathrm{O}-\mathrm{Zr}$ bonds $(532.00 \mathrm{eV})$ was determined from the $\mathrm{O} 1 \mathrm{~s}$ spectra of $\mathrm{w} / \mathrm{o}^{-}$ UC-3 and UC-3. These analytical results definitely show that the coordination vacancies are caused by removing benzoic acid linkers. For the S 2p spectra (in Fig. 4d), an obvious chemical peak at a lower energy level $(163.37 \mathrm{eV})$ is observed in the S@UC3 compared with that of elemental sulfur, indicating a strong chemical interaction between sulfur and the $\mathrm{Zr}^{4+}$ in UC-3.

Electrochemical tests were carried out to evaluate the merits of using the UC series in Li-S batteries. Fig. 5 a shows the cyclic voltammogram (CV) curves of the S@UC series and S@CNTs in the voltage range of 1.7-2.8 V. For the three S@UC hybrids, typical CV features of sulfur cathodes were observed, with two characteristic peaks in the reduction process attributed to the transformation of ring-shaped $\mathrm{S}_{8}$ to long-chain $\mathrm{Li}_{2} \mathrm{~S}_{x}(4<x<8)$ and a further reduction to lower-order $\mathrm{Li}_{2} \mathrm{~S}_{2} / \mathrm{Li}_{2} \mathrm{~S}$ and two oxidation peaks ascribed to the conversion of $\mathrm{Li}_{2} \mathrm{~S}_{2} / \mathrm{Li}_{2} \mathrm{~S}$ to higher-order $\mathrm{Li}_{2} \mathrm{~S}_{n}(n>2)$ and the ultimate formation of sulfur. For the S@CNTs hybrid, excess filling of sulfur into CNTs seriously suppress the electrochemistry of the electrode, leading to the lower reduction and higher oxidation potentials of S@CNTs than those of the S@UC series. Noticeably, from the 2nd to the 

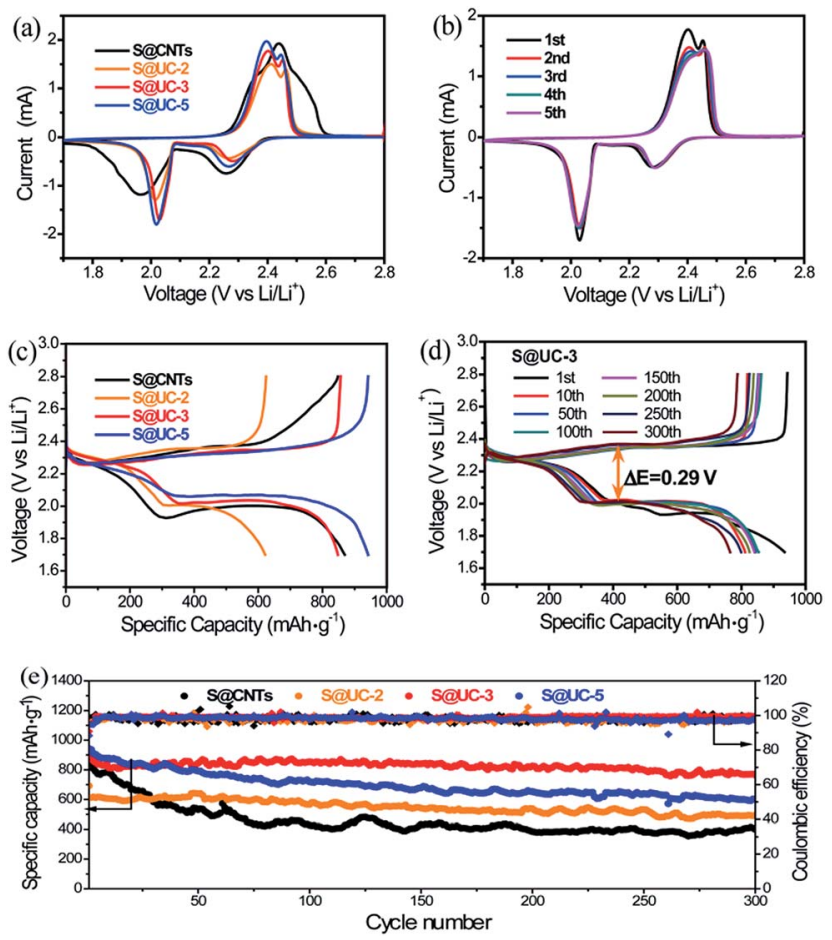

Fig. 5 (a) and (c) Representative cyclic voltammetry curves and galvanostatic charge-discharge voltage profiles of the S@UC series and SaCNTs cathodes at $0.5 \mathrm{~A} \mathrm{~g}^{-1}$. (b) and (d) Cyclic voltammetry curves and galvanostatic charge-discharge voltage profiles of the SaUC-3 cathode at $0.5 \mathrm{~A} \mathrm{~g}^{-1}$. (e) Cycling performances of the S@UC series and SaCNTs cathodes at $0.5 \mathrm{~A} \mathrm{~g}^{-1}$ after 300 cycles.

5th cycle of the S@UC-3 cathode, the almost overlapping curves reveal an effective suppression of the electrochemical polarization by the UC series, as shown in Fig. 5b. The representative galvanostatic charge-discharge profiles of S@UC cathodes between 1.7 and $2.8 \mathrm{~V}$ at $0.5 \mathrm{~A} \mathrm{~g}^{-1}$ are shown in Fig. 5c. All cathodes exhibit two typical discharging plateaus $(\sim 2.3 \mathrm{~V}$ and $\sim 2.0 \mathrm{~V} v s . \mathrm{Li} / \mathrm{Li}^{+}$) corresponding to the multi-step reduction from sulfur to $\mathrm{Li}_{2} \mathrm{~S}$ during the discharging process. Fig. $\mathrm{S} 5 \dagger$ and $5 \mathrm{~d}$ show several representative charge-discharge profiles of the three S@UC hybrids and the S@CNTs hybrid at $0.5 \mathrm{~A} \mathrm{~g}^{-1}$. The S@UC hybrids exhibit obvious shrinkage $(\Delta E \approx 0.29 \mathrm{eV})$ of both the upper and lower discharge plateaus compared to that of the S@CNTs hybrid $(\Delta E>0.5 \mathrm{eV})$, resulting from the effective curbing of the loss of active material and relieving of the aggregation of insulating $\mathrm{Li}_{2} \mathrm{~S}_{2} / \mathrm{Li}_{2} \mathrm{~S}$ on the surface of the electrodes. The cycling performances of the S@UC and S@CNTs hybrids at $0.5 \mathrm{~A} \mathrm{~g}^{-1}$ are displayed in Fig. 5e, indicating an initial specific capacity of $691 \mathrm{~mA} \mathrm{~h} \mathrm{~g}^{-1}$ (S@UC-2), $925 \mathrm{~mA} \mathrm{~h} \mathrm{~g}$ (S@UC-3) and $942 \mathrm{~mA} \mathrm{~h} \mathrm{~g}^{-1}$ (S@UC-5) and a capacity retention of $493 \mathrm{~mA} \mathrm{~h} \mathrm{~g}^{-1}, 765 \mathrm{~mA} \mathrm{~h} \mathrm{~g}^{-1}$ and $600 \mathrm{~mA} \mathrm{~h} \mathrm{~g}^{-1}$ after 300 cycles, respectively. Undoubtedly, the S@CNTs electrode shows fast capacity recession with a serious fading rate of $0.180 \%$ per cycle. After undergoing fast capacity fading in the first several cycles, S@UC-2 and S@UC-3 displayed a very stable cycling performance with a capacity decay of only $0.068 \%$ and $0.028 \%$, respectively, per cycle after the 5 th cycle. However, the capacity of S@UC-5 still declined at a fast rate of $0.108 \%$, resulting from the over-dose addition of nonpolar CNTs degenerating the chemisorption of LiPSs on UC-5. Fig. S6a† exhibits a clean separator without distinct traces of the dissolved LiPSs, implying an effective restriction of LiPSs in the S@UC-3 cathode. Meanwhile for S@CNTs, orange LiPSs exist over a large area on the separator, as shown in Fig. S6b. $\dagger$ More importantly, almost no variation of the UC-3 composite compared with the pristine state was clearly shown in the SEM images after 300 cycles (Fig. S6c-h $\dagger$ ), indicating the excellent mechanical stability of the UC-3 architecture for withstanding large volume deformation during cycling processes. Considering the terrible conductivity of UiO-66, the cycling performances of S@UiO-66, S@CNTs and S@UC-3 electrodes were measured at a low current density of $0.1 \mathrm{~A} \mathrm{~g}^{-1}$ to rightly determine the enhanced chemisorption of polysulfides, as shown in Fig. S7. $\uparrow$ S@UC-3 delivered a high initial capacity of $1045 \mathrm{~mA} \mathrm{~h} \mathrm{~g}{ }^{-1}$ based on that of S@UiO-66 (670 mA h g $\left.{ }^{-1}\right)$, and still maintained a high retention of $897 \mathrm{~mA} \mathrm{~h} \mathrm{~g}^{-1}$ after 100 cycles, showing a lower decay rate of $0.14 \%$ per cycle than those of S@CNTs (0.35\% per cycle) and S@UiO-66 (0.30\% per cycle).

Electrochemical impedance spectroscopy (EIS) (Fig. 6a) shows an internal resistance order of S@UC-2 > S@CNTs > S@UC-3 > S@UC-5, supporting the capacity performance comparison. Rate performance was tested in the S@UC-3 hybrid at various current densities from $0.1 \mathrm{~A} \mathrm{~g}^{-1}$ to $2 \mathrm{~A} \mathrm{~g}^{-1}$ (Fig. 6b), delivering reversible capacities of $1058 \mathrm{~mA} \mathrm{~h} \mathrm{~g}^{-1}, 915 \mathrm{~mA} \mathrm{~h} \mathrm{~g}^{-1}$, $752 \mathrm{~mA} \mathrm{~h} \mathrm{~g}^{-1}$ and $612 \mathrm{~mA} \mathrm{~h} \mathrm{~g}^{-1}$ at current densities of $0.1 \mathrm{~A} \mathrm{~g}^{-1}$, $0.2 \mathrm{~A} \mathrm{~g}^{-1}, 0.5 \mathrm{~A} \mathrm{~g}^{-1}$ and $1 \mathrm{~A} \mathrm{~g}^{-1}$, respectively. Even increasing further to $2 \mathrm{~A} \mathrm{~g}^{-1}$, a high capacity of $411 \mathrm{~mA} \mathrm{~h} \mathrm{~g}{ }^{-1}$ can be still retained. When current density is reduced abruptly back to $0.2 \mathrm{Ag}^{-1}$, S@UC-3 can recover back to $857 \mathrm{~mA} \mathrm{~h} \mathrm{~g}^{-1}$, most of the original capacity. Conversely, S@CNTs shows capacity instability at a low current density of $0.1 \mathrm{~A} \mathrm{~g}^{-1}$ and a sharp capacity drop between $1 \mathrm{~A} \mathrm{~g}^{-1}$ and $2 \mathrm{~A} \mathrm{~g}^{-1}$.
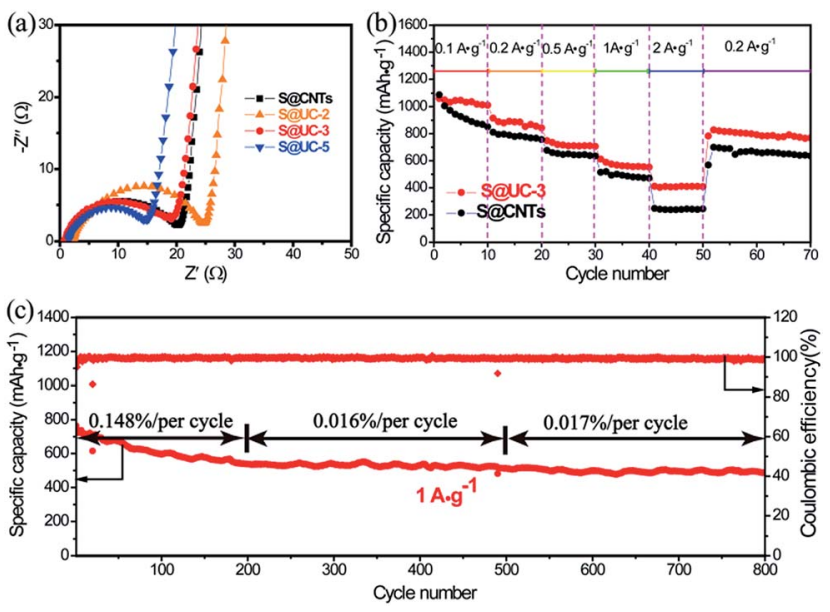

Fig. 6 (a) Nyquist plots of SaCNTs, S@UC-2, S@UC-3 and S@UC-5 electrodes. (b) Rate performances of S@CNTs and SAUC-3 electrodes. (c) Long cycling performance of the S@UC-3 electrode over 800 cycles at $1 \mathrm{~A} \mathrm{~g}^{-1}$. 
Longer cycling has been achieved at a high current density of $1 \mathrm{~A} \mathrm{~g}^{-1}$ using the S@UC-3 hybrid as the cathode (Fig. 6c), showing a high initial capacity of $764 \mathrm{~mA} \mathrm{~h} \mathrm{~g}^{-1}$ and very low fading rate of $0.07 \%$ per cycle after 800 cycles. In the first 200 cycles, the cell displays deterioration of the capacity with a decay rate of $0.148 \%$ per cycle, which may result from the irreversible loss of sulfur outside the UiO-66 framework during cycling. However, wonderful cycling stability with a low fading rate of $0.016 \%$ is obtained over the next 300 cycles due to the strong LiPS trapping effect. The S@UC-3 cathode still keeps a capacity decay rate as low as $0.017 \%$ per cycle over the last 300 cycles, which may owe more to the good mechanical performance of the UC architectures.

In order to further understand and confirm the role of coordination defects in trapping LiPSs, first principles calculations based on density functional theory (DFT) were performed. We set up models between several groups of UiO-66 with zero (intact UiO-66, in Fig. S8†), one, two and three linker-missing defects (denoted $\mathrm{D}_{n}$-UiO-66, $n=1,2$ and 3, in Fig. S9†) and $\mathrm{Li}_{2} \mathrm{~S}_{4}$ (as a representative LiPS) to confirm the role of the coordination defects in trapping LiPSs, as shown in Fig. 7a-d. For pristine UiO-66, the inner cluster is occupied by 12 linkers with full coordination, and thus has no active site. Moreover, fully coordinated linkers form very closely-packed obstacles to the approach of $\mathrm{Li}_{2} \mathrm{~S}_{4}$ molecules to the core. The linker vacancies not only create the active sites, but also effectively reduce the number of obstacles and enlarge the inner cavities. ${ }^{63,64}$ Thus, $\mathrm{Li}_{2} \mathrm{~S}_{4}$ molecules easily reach and interact with the inner cluster. As expected, the computational results (Fig. 7e) show a stronger affinity of $\mathrm{D}_{n}$-UiO-66 than intact UiO-66 to the $\mathrm{Li}_{2} \mathrm{~S}_{4}$ molecule. However, increasing linker-missing defects cause a counteracting effect on the adsorption of $\mathrm{Li}_{2} \mathrm{~S}_{4}$, leading to weakening binding energy. Surprisingly, intact UiO-66 still exhibits a decent binding energy $(\sim 2.0 \mathrm{eV})$ for $\mathrm{Li}_{2} \mathrm{~S}_{4}$, which is mainly attributed to the strong attraction of abundant electrons from the benzene ring of the linkers to the $\mathrm{Li}$ cations of $\mathrm{Li}_{2} \mathrm{~S}_{4}$. Moreover, a static $\mathrm{Li}_{2} \mathrm{~S}_{6}$ adsorption test was conducted to investigate the adsorption capacity of the UC series for LiPSs. Fig. $7 f$ clearly shows the changes in $\mathrm{Li}_{2} \mathrm{~S}_{6}$ absorption in the UC series and control groups of UiO-66 and CNTs, which reveals the adsorption capacity order of the samples, UC- $2=$ UC- $3>$ UC- $5=$ UiO-66 >> CNTs, and thus demonstrates a significantly stronger affinity of $\mathrm{Li}_{2} \mathrm{~S}_{6}$ molecules with the UC series than with pristine UiO-66 or nonpolar carbon materials. Hence, the coordination defects distinctly promote the chemisorption kinetics of the UC composites for $\mathrm{Li}_{2} \mathrm{~S}_{6}$. However, it is notable that an excess content of nonpolar CNTs would badly weaken the adsorption capacity of the UC composite (like UC-5).

Generally, the multi-functionalized UC composite as a sulfur host has achieved dramatically improved capacity and cycling performances. In particular, the cycling stability of the S@UC-3 electrode surpasses most MOF-based sulfur electrodes (Table $\mathrm{S} 3 \dagger$ ) and representative MOF-derived carbon electrodes (Table S4†), and can be competitive with typical metallide electrodes with strong chemisorption for LiPSs (Table S5 $†$ ). Furthermore, DFT calculations adequately reveal the mechanism of LiPS adsorption onto the linker-defective UiO-66. Despite the computational result that the intensive loss of several adjacent

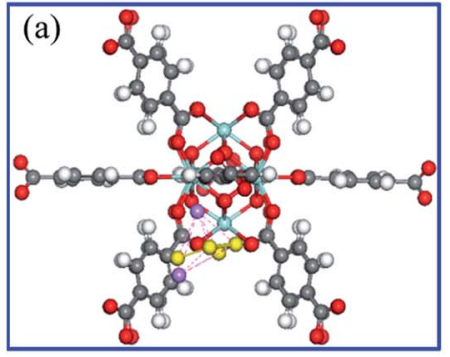

Uio-66/Li ${ }_{2} \mathrm{~S}_{4}$

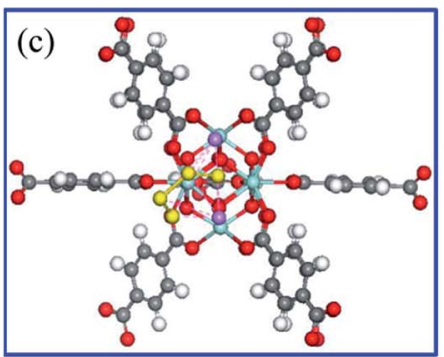

$\mathrm{D}_{2}$-Uio-66/Li $\mathrm{L}_{4}$

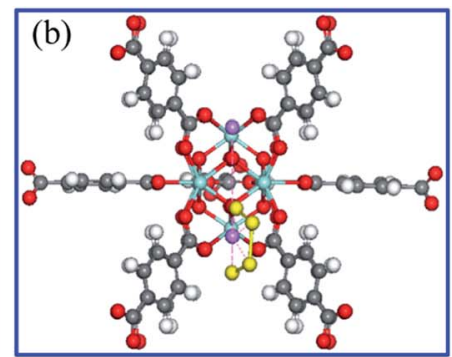

$D_{1}-$ Uio-66/Li $\mathrm{L}_{4}$

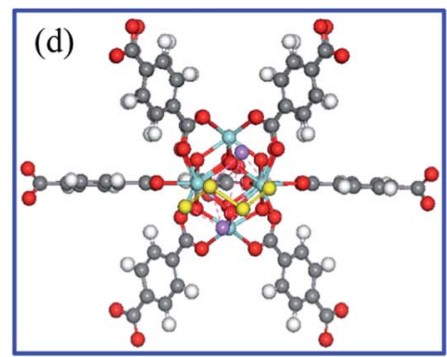

$\mathrm{D}_{3}$-Uio-66/Li $\mathrm{S}_{4}$

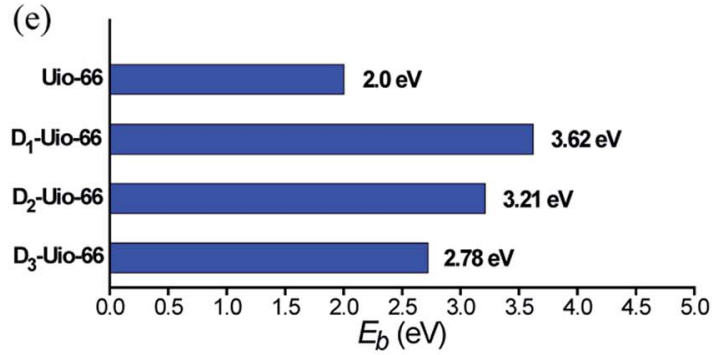

(f)

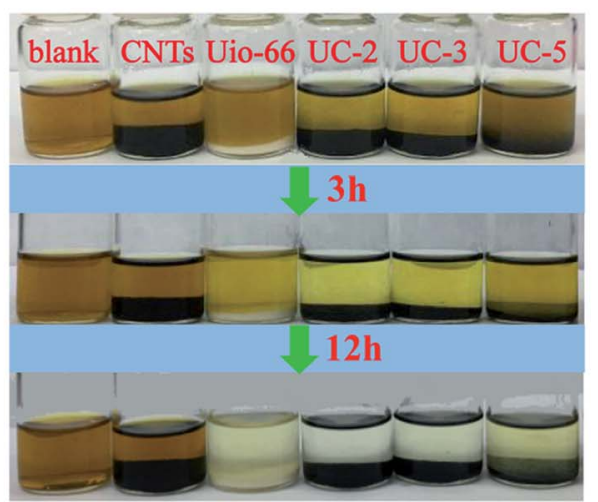

Fig. 7 (a)-(d) Atomic model configurations showing the interaction mechanism between $\mathrm{Li}_{2} \mathrm{~S}_{4}$ (as the representative soluble LiPSs) and UiO-66 and the defective UiO-66 with one, two and three ligands missing (denoted $\mathrm{D}_{1}-\mathrm{UiO}-66, \mathrm{D}_{2}-\mathrm{UiO}-66$ and $\mathrm{D}_{3}-\mathrm{UiO}-66$, respectively) and (e) their binding energy. Gray, red, white, yellow and light blue spheres represent $\mathrm{C}, \mathrm{O}, \mathrm{H}, \mathrm{Li}$ and $\mathrm{Zr}$ atoms, respectively. (f) $\mathrm{Changes}$ in $\mathrm{Li}_{2} \mathrm{~S}_{6}$ adsorption in UiO-66, CNTs and the UC series with time. 
linkers in a UiO-66 unit would cause a weakening of the entrapment of LiPSs, it is hard for this to happen in the synthesis of these materials considering the stability of MOF coordination. Due to the much greater ligand connection, it is entirely possible that one linker or two nonadjacent linkers were artificially removed from a UiO-66 unit without compromising the structural stability, which substantially increases the amount of effective active sites.

\section{Conclusion}

In this paper, the competitive coordination principle is introduced for the first time in Li-S batteries to design and fabricate a class of linker-missing UiO-66/CNT (UC) composites as the sulfur hosts. Meanwhile, we also achieved a combination of high electronic conductivity, excellent structural stability, and strong chemisorption via a facile synthesis. Finally, the S@UC-3 hybrid, as the best optimization, achieved significantly improved electrochemical dynamics of the sulfur reaction and excellent cycling stability. Most strikingly, theoretical studies unveil a strong chemical affinity between UiO-66 with linkermissing defects and polysulfides, which fundamentally demonstrates the electrochemical mechanism and validly supports the experimental cell results.

\section{Conflicts of interest}

The authors declare no conflict of interest.

\section{Acknowledgements}

This work was supported by the National Key R\&D Program of China (No. 2016YFB0100400).

\section{Notes and references}

1 S. Evers and L. F. Nazar, Acc. Chem. Res., 2013, 46, 1135-1143.

2 Y. Yang, G. Y. Zheng and Y. Cui, Chem. Soc. Rev., 2013, 42, 3018-3032.

3 B. Ding, C. Yuan, L. Shen, G. Xu, P. Nie and X. Zhang, Chem.Eur. J., 2013, 19, 1013-1019.

4 Z. W. Seh, Y. Sun, Q. Zhang and Y. Cui, Chem. Soc. Rev., 2016, 45, 5605-5634.

5 J. Zhang, H. Huang, J. Bae, S. H. Chung, W. Zhang, A. Manthiram and G. Yu, Small Methods, 2017, 2, 1700279.

6 P. G. Bruce, S. A. Freunberger, L. J. Hardwick and J. M. Tarascon, Nat. Mater., 2011, 11, 19-29.

7 Y.-X. Yin, S. Xin, Y.-G. Guo and L.-J. Wan, Angew. Chem., Int. Ed., 2013, 52, 13186-13200.

8 L. Ma, K. E. Hendrickson, S. Wei and L. A. Archer, Nano Today, 2015, 10, 315-338.

9 M. A. Pope and I. A. Aksay, Adv. Energy Mater., 2015, 5, 1500124.

10 Q. Pang, X. Liang, C. Y. Kwok and L. F. Nazar, Nat. Energy, 2016, 1, 16132.

11 S. Rehman, K. Khan, Y. Zhao and Y. Hou, J. Mater. Chem. A, 2017, 5, 3014-3038.
12 X. Liu, J.-Q. Huang, Q. Zhang and L. Mai, Adv. Mater., 2017, 29, 1601759.

13 Y. Zhao, W. Wu, J. Li, Z. Xu and L. Guan, Adv. Mater., 2014, 26, 5113-5118.

14 M. Yu, R. Li, M. Wu and G. Shi, Energy Storage Materials, 2015, 1, 51-73.

15 J. Schuster, G. He, B. Mandlmeier, T. Yim, K. T. Lee, T. Bein and L. F. Nazar, Angew. Chem., 2012, 124, 3651-3655.

16 H.-J. Peng, J.-Q. Huang, M.-Q. Zhao, Q. Zhang, X.-B. Cheng, X.-Y. Liu, W.-Z. Qian and F. Wei, Adv. Funct. Mater., 2014, 24, 2772-2781.

17 Q. Li, Z. Zhang, K. Zhang, J. Fang, Y. Lai and J. Li, J. Power Sources, 2014, 256, 137-144.

18 J. Zhang, J. Xiang, Z. Dong, Y. Liu, Y. Wu, C. Xu and G. Du, Electrochim. Acta, 2014, 116, 146-151.

19 J. Zhang, Z. Dong, X. Wang, X. Zhao, J. Tu, Q. Su and G. Du, J. Power Sources, 2014, 270, 1-8.

20 C. Xu, Y. Wu, X. Zhao, X. Wang, G. Du, J. Zhang and J. Tu, J. Power Sources, 2015, 275, 22-25.

21 Q. Pang, X. Liang, C. Y. Kwok and L. F. Nazar, J. Electrochem. Soc., 2015, 162, A2567-A2576.

22 T. Chen, B. Cheng, G. Zhu, R. Chen, Y. Hu, L. Ma, H. Lv, Y. Wang, J. Liang, Z. Tie, Z. Jin and J. Liu, Nano Lett., 2017, 17, 437-444.

23 Z. Wei Seh, W. Li, J. J. Cha, G. Zheng, Y. Yang, M. T. McDowell, P.-C. Hsu and Y. Cui, Nat. Commun., 2013, 4, 1331.

24 X. Liang, C. Y. Kwok, F. Lodi-Marzano, Q. Pang, M. Cuisinier, H. Huang, C. J. Hart, D. Houtarde, K. Kaup, H. Sommer, T. Brezesinski, J. Janek and L. F. Nazar, Adv. Energy Mater., 2016, 6, 1501636.

25 J. Zhang, Y. Shi, Y. Ding, W. Zhang and G. Yu, Nano Lett., 2016, 16, 7276-7281.

26 L. Ma, R. Chen, G. Zhu, Y. Hu, Y. Wang, T. Chen, J. Liu and Z. Jin, ACS Nano, 2017, 11, 7274-7283.

27 Z. W. Seh, J. H. Yu, W. Li, P.-C. Hsu, H. Wang, Y. Sun, H. Yao, Q. Zhang and Y. Cui, Nat. Commun., 2014, 5, 5017.

28 Z. Yuan, H.-J. Peng, T.-Z. Hou, J.-Q. Huang, C.-M. Chen, D.-W. Wang, X.-B. Cheng, F. Wei and Q. Zhang, Nano Lett., 2016, 16, 519-527.

29 Q. Pang, D. Kundu and L. F. Nazar, Mater. Horiz., 2016, 3, 130-136.

30 T. Lei, W. Chen, J. Huang, C. Yan, H. Sun, C. Wang, W. Zhang, Y. Li and J. Xiong, Adv. Energy Mater., 2017, 7, 1601843.

31 C. Ye, L. Zhang, C. Guo, D. Li, A. Vasileff, H. Wang and S.-Z. Qiao, Adv. Funct. Mater., 2017, 27, 1702524.

32 Z. Cui, C. Zu, W. Zhou, A. Manthiram and J. B. Goodenough, Adv. Mater., 2016, 28, 6926-6931.

33 Z. Sun, J. Zhang, L. Yin, G. Hu, R. Fang, H.-M. Cheng and F. Li, Nat. Commun., 2017, 8, 14627.

34 Q. Pang, X. Liang, C. Y. Kwok, J. Kulisch and L. F. Nazar, Adv. Energy Mater., 2017, 7, 1601630.

35 D.-R. Deng, F. Xue, Y.-J. Jia, J.-C. Ye, C.-D. Bai, M.-S. Zheng and Q.-F. Dong, ACS Nano, 2017, 11, 6031-6039.

36 W. Li, Q. Zhang, G. Zheng, Z. W. Seh, H. Yao and Y. Cui, Nano Lett., 2013, 13, 5534-5540. 
37 J. Shao, X. Li, L. Zhang, Q. Qu and H. Zheng, Nanoscale, 2013, 5, 1460-1464.

38 X. Liang, A. Garsuch and L. F. Nazar, Angew. Chem., Int. Ed., 2015, 54, 3907-3911.

39 X. Liang, Y. Rangom, C. Y. Kwok, Q. Pang and L. F. Nazar, Adv. Mater., 2017, 29, 1603040.

40 Z. Wang, X. Li, Y. Cui, Y. Yang, H. Pan, Z. Wang, C. Wu, B. Chen and G. Qian, Cryst. Growth Des., 2013, 13, 51165120 .

41 J. Zheng, J. Tian, D. Wu, M. Gu, W. Xu, C. Wang, F. Gao, M. H. Engelhard, J.-G. Zhang, J. Liu and J. Xiao, Nano Lett., 2014, 14, 2345-2352.

42 J. Zhou, R. Li, X. Fan, Y. Chen, R. Han, W. Li, J. Zheng, B. Wang and X. Li, Energy Environ. Sci., 2014, 7, 2715-2724.

43 Z. Wang, B. Wang, Y. Yang, Y. Cui, Z. Wang, B. Chen and G. Qian, ACS Appl. Mater. Interfaces, 2015, 7, 20999-21004.

44 H. Park and D. J. Siegel, Chem. Mater., 2017, 29, 4932-4939. 45 Y. Hou, H. Mao and L. Xu, Nano Res., 2017, 10, 344-353.

46 X. Cao, C. Tan, M. Sindoro and H. Zhang, Chem. Soc. Rev., 2017, 46, 2660-2677.

47 J. H. Cavka, S. Jakobsen, U. Olsbye, N. Guillou, C. Lamberti, S. Bordiga and K. P. Lillerud, J. Am. Chem. Soc., 2008, 130, 13850-13851.

48 H. Wu, T. Yildirim and W. Zhou, J. Phys. Chem. Lett., 2013, 4, 925-930.

49 Q. Zhao, W. Yuan, J. Liang and J. Li, Int. J. Hydrogen Energy, 2013, 38, 13104-13109.

50 W. Bao, Z. Zhang, Y. Qu, C. Zhou, X. Wang and J. Li, J. Alloys Compd., 2014, 582, 334-340.

51 K. M. Choi, H. M. Jeong, J. H. Park, Y.-B. Zhang, J. K. Kang and O. M. Yaghi, ACS Nano, 2014, 8, 7451-7457.
52 Y. Mao, G. Li, Y. Guo, Z. Li, C. Liang, X. Peng and Z. Lin, Nat. Commun., 2017, 8, 14628.

53 H. B. Wu, S. Wei, L. Zhang, R. Xu, H. H. Hng and X. W. Lou, Chem.-Eur. J., 2013, 19, 10804-10808.

54 X. Yang, N. Yan, W. Zhou, H. Zhang, X. Li and H. Zhang, J. Mater. Chem. A, 2015, 3, 15314-15323.

55 S. Cai, X. Wang, M. Chen, J. Liu, Q. Lu and S. Wei, J. Electrochem. Soc., 2016, 163, A2922-A2929.

56 Z. Li, C. Li, X. Ge, J. Ma, Z. Zhang, Q. Li, C. Wang and L. Yin, Nano Energy, 2016, 23, 15-26.

57 G. Kresse and J. Hafner, Phys. Rev. B: Condens. Matter Mater. Phys., 1993, 47, 558-561.

58 P. E. Blöchl, Phys. Rev. B: Condens. Matter Mater. Phys., 1994, 50, 17953-17979.

59 J. P. Perdew, K. Burke and M. Ernzerhof, Phys. Rev. Lett., 1996, 77, 3865-3868.

60 G. Kresse and D. Joubert, Phys. Rev. B: Condens. Matter Mater. Phys., 1999, 59, 1758-1775.

61 J. Neugebauer and M. Scheffler, Phys. Rev. B: Condens. Matter Mater. Phys., 1992, 46, 16067-16080.

62 H.-L. Jiang, D. Feng, T.-F. Liu, J.-R. Li and H.-C. Zhou, J. Am. Chem. Soc., 2012, 134, 14690-14693.

63 F. Vermoortele, B. Bueken, G. Le Bars, B. Van de Voorde, M. Vandichel, K. Houthoofd, A. Vimont, M. Daturi, M. Waroquier, V. Van Speybroeck, C. Kirschhock and D. E. De Vos, J. Am. Chem. Soc., 2013, 135, 11465-11468.

64 H. Wu, Y. S. Chua, V. Krungleviciute, M. Tyagi, P. Chen, T. Yildirim and W. Zhou, J. Am. Chem. Soc., 2013, 135, 10525-10532.

65 S. Ling and B. Slater, Chem. Sci., 2016, 7, 4706-4712. 